\title{
Tensile Properties of AM Maraging steel
}

\author{
Philip Church $^{1 *}$, Mark Reynolds ${ }^{1}$, Peter Gould ${ }^{2}$, Robin Oakley ${ }^{3}$, Nigel Harrison ${ }^{3}$, Dave Williamson ${ }^{4}$, Chris $_{\text {Braithwaite }}^{4}$, \\ Nick Taylor ${ }^{4}$ \\ ${ }^{1}$ QinetiQ, Fort Halstead, Sevenoaks, Kent, TN14 7BP, UK \\ ${ }^{2}$ QinetiQ, Bristol Business Park, Coldharbour Lane, Bristol, BS16 1FJ, UK \\ ${ }^{3}$ QinetiQ, Cody Technology Park, Ively Road, Farnborough, Hampshire, GU14 0LX, UK \\ ${ }^{4}$ Surface, Microstructure \& Fracture Group Cavendish Laboratory, JJ Thomson Ave, Cambridge, CB3 0HE, UK.
}

\begin{abstract}
Additively Manufactured (AM) materials have great potential for producing graded materials, embedded structures and near net complex shapes. AM maraging steel properties have been compared with wrought maraging steel. The comparison featured interrupted tensile tests over a range of temperatures and strain rates. In addition a specially designed Tensile Split Hopkinson Pressure Bar (TSHPB) has been built to test very high strength metals at high strain rates. The results showed that the AM maraging steel was much more ductile than expected and exhibited significant necking under all conditions tested. All the samples exhibited ductile fracture. Although not as ductile as the wrought material, the AM material could be cost effective through economies of scale for complex components. The microstructure contained inclusions which derived from either the powder or the AM process and thus there is significant potential to improve these materials further. A modified Armstrong-Zerilli model was also constructed for these materials and shown to predict the raw experimental data within experimental error using DYNA3D simulations.
\end{abstract}

\section{Introduction}

There is extensive interest in Additive Manufacture (AM) of metals as AM technology is developing very rapidly. The development of AM opens the door to new and novel materials and more flexible manufacturing processes. Whilst there have been previous studies on the properties of AM metals, most have focussed on microstructure and static properties [1-2]. The purpose of this paper is to compare the tensile properties of AM maraging steel with equivalent wrought maraging steel over a range of strain rates.

\subsection{Material Supply}

The AM material was manufactured using Selective Laser Melting (SLM) and subjected to a standard ageing heat treatment process. This ensured the properties were similar to the wrought material. The wrought and AM maraging steel had hardnesses of $628 \mathrm{Hv}$ and $637 \mathrm{Hv}$, respectively. The AM tensile test samples were machined from a $10 \mathrm{~mm}$ thick plate in both directions (i.e. $\mathrm{x}$ and $\mathrm{y}$ ) so that the effect of anisotropy on the results could be assessed. No samples were manufactured in the build (i.e. $\mathrm{z}$ direction) for this investigation.

All the materials were fully dense with a range of 8.09-8.11 g.cm $\mathrm{gm}^{-3}$ and within the standard composition specification.

\section{Quasi-Static Tensile Test Results}

The AM and wrought maraging steel samples were subjected to interrupted tensile tests to determine their isothermal response. These tests were performed under quasi-static (QS) loading at room temperature, QS at 100 ${ }^{\circ} \mathrm{C}$ and a strain rate of $1 \mathrm{~s}^{-1}$. The results are shown in Table 1.

Table 1. Results of QS interrupted tensile tests.

\begin{tabular}{|c|c|c|c|}
\hline Property & $\begin{array}{c}\text { AM } \\
\text { X- } \\
\text { axis }\end{array}$ & $\begin{array}{c}\text { AM } \\
\text { Y- } \\
\text { axis }\end{array}$ & $\begin{array}{c}\text { Wrought } \\
\text { bar }\end{array}$ \\
\hline \multicolumn{4}{|c|}{ Room temperature QS strain rate } \\
\hline \multirow{2}{*}{ Young's Modulus (GPa) } & 183 & 188 & \multirow{2}{*}{185} \\
\hline & 185 & 187 & \\
\hline \multirow{2}{*}{$0.2 \%$ proof stress $(\mathrm{MPa})$} & 2030 & 2050 & \multirow{2}{*}{1970} \\
\hline & 2012 & 2033 & \\
\hline \multirow{2}{*}{$\begin{array}{l}\text { Tensile strength } R_{m} \\
\text { (MPa) }\end{array}$} & 2105 & 2125 & \multirow{2}{*}{2022} \\
\hline & 2085 & 2105 & \\
\hline \multirow{2}{*}{ Elongation $\%$} & 4.8 & 4.3 & \multirow{2}{*}{8.5} \\
\hline & 3.7 & 4.0 & \\
\hline
\end{tabular}

Corresponding author: pdchurch@qinetiq.com 


\begin{tabular}{|c|c|c|c|}
\hline \multirow{2}{*}{ Reduction of area $\%$} & 28 & 29 & \multirow{2}{*}{60} \\
\hline & 24 & 28 & \\
\hline \multicolumn{4}{|l|}{$+100^{\circ} \mathrm{C}$ QS strain rate } \\
\hline Tensile strength $(\mathrm{MPa})$ & 2005 & 1996 & 1962 \\
\hline Elongation \% & 4.7 & 4.6 & 9.5 \\
\hline Reduction of area $\%$ & 25 & 27 & 60 \\
\hline \multicolumn{4}{|c|}{ Room temperature $1 \mathrm{~s}^{-1}$ strain rate } \\
\hline \multirow{2}{*}{ Tensile strength (MPa) } & 2169 & 2145 & \multirow{2}{*}{2138} \\
\hline & 2170 & 2126 & \\
\hline \multirow{2}{*}{ Elongation \% } & 4.1 & 4.3 & \multirow{2}{*}{7.9} \\
\hline & 5.0 & 4.8 & \\
\hline \multirow{2}{*}{ Reduction of area \% } & 27 & 42 & \multirow{2}{*}{60} \\
\hline & 34 & 33 & \\
\hline
\end{tabular}

The AM material has a consistently higher proof stress and Ultimate Tensile Strength (UTS) than the wrought material. Surprisingly the elongation of the AM material is consistently higher (i.e. $4-5 \%$ ) than those expected from the literature (i.e. 1.5\%). This is illustrated for the neck formation as shown in Figure 1. Similar observations were made for the other test conditions.
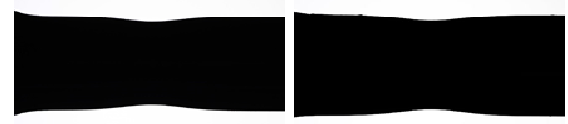

AN $X$-axis

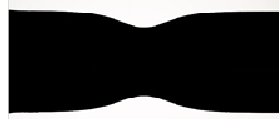

Wrough: bar C3J0
Fig. 1. Comparison of necks between AM and wrought maraging steel for QS interrupted tensile test at room temperature.

Whilst the AM maraging steel was not as ductile as the wrought material, the results for the AM material are very encouraging and give potential for the production of maraging steels of very high strength and ductility (i.e. local strains $>0.3$ ), which would be useful in a range of applications. The isothermal stress versus strain curves are shown in Figure 2 for the AM and wrought maraging steel, demonstrating the classic parallel nature of the isothermal curves after the yield point.

These results demonstrate that the flow stress of the AM material is consistently higher than the wrought material. The wrought material has a much higher failure strain of 0.7 compared to about 0.3 for the AM material. There was no evidence of anisotropy affecting the results.

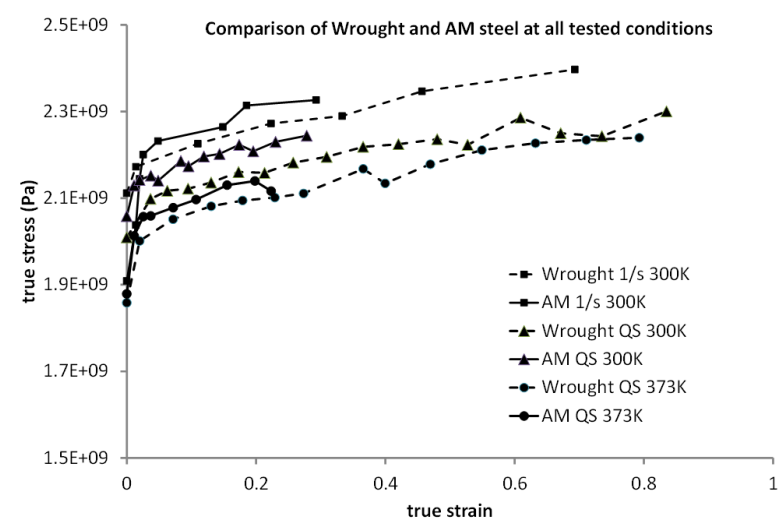

Fig. 2. Comparison of isothermal stress v strain curves for AM and wrought maraging steel.

\subsection{Model Development}

The data from the QS interrupted testing was used to determine the constants for the modified ArmstrongZerilli (A/Z) model $[3,4]$. The model is described by the following equation

$$
\sigma=\left(C_{0}+C_{1} \varepsilon^{n}\right) \mu_{T} / \mu_{293}+C_{2} \exp \left(-C_{3} T+C_{4} T \log \varepsilon\right)
$$

Where $\mathrm{C}_{\mathrm{o}}$ to $\mathrm{C}_{4}$ and $\mathrm{n}$ are constants and $\sigma, \mathcal{E}, \dot{\mathcal{\varepsilon}}$ and $\mathrm{T}$ are respectively stress, strain, strain rate and temperature in Kelvin $(\mathrm{K})$ with $\mu_{293}$ the shear modulus at $293 \mathrm{~K}$ and $\mu_{T}$ the shear modulus at the current temperature. The constants are directly measured from the interrupted tensile tests and are obtained by rearranging equation (1) and calculating slopes and intercepts [4]. The modified $\mathrm{A} / \mathrm{Z}$ model is run in conjunction with a shock equation of state (e.g. MieGruneisen) to describe the hydrostatic response.

These materials fail by a ductile fracture mechanism based on the growth, coalescence and nucleation of voids in the deformation regimes of interest. The Goldthorpe Path Dependent Fracture (PDF) model has been developed for ductile fracture processes [5] and is based on a novel correction term for the stresses in a sharp neck in a tensile specimen, which can be applied to void growth. The model has been applied to the growth and nucleation of voids under different stress systems and has also been used to successfully analyse the classic Bridgeman data for steels [6]. The model accumulates damage according to the following relationship:-

$$
d S=0.67 \exp \left(1.5 \sigma_{n}-0.04 \sigma_{n}^{-1.5}\right) d \varepsilon+A \varepsilon_{s}
$$

$\sigma_{\mathrm{n}}=$ Stress triaxiality (Pressure/Flow Stress or $\mathrm{P} / \mathrm{Y}$ )

$\mathrm{d} \varepsilon=$ Effective plastic strain increment

$\varepsilon_{\mathrm{s}}=$ maximum principle shear strain

$\mathrm{A}=$ Constant determined from torsion test

$\mathrm{S}=$ Damage

The damage $\mathrm{S}$ is then by 


$$
S_{\text {new }}=S_{\text {old }}+d S
$$

Fracture occurs when the damage reaches a critical value void fracture number (vfn), which is determined from a QS tension test. The damage comprises a tensile component due to void growth and a shear component due to shear localisation.

The constants for the modified $\mathrm{A} / \mathrm{Z}$ model are given in Table 2.

Table 2. Constants for AM and wrought maraging steel.

\begin{tabular}{|l|l|l|}
\hline Parameter & $\begin{array}{c}\text { AM } \\
\text { maraging } \\
\text { steel }\end{array}$ & $\begin{array}{c}\text { Wrought } \\
\text { maraging steel }\end{array}$ \\
\hline $\mathrm{Co}(\mathrm{MPa})$ & 2020 & 1960 \\
\hline $\mathrm{C} 1(\mathrm{MPa})$ & 300 & 300 \\
\hline $\mathrm{C} 2(\mathrm{MPa})$ & 580 & 580 \\
\hline $\mathrm{C} 3\left(\mathrm{~K}^{-1}\right)$ & 0.005 & 0.005 \\
\hline $\mathrm{C} 4\left(\mathrm{~K}^{-1}\right)$ & 0.0003 & 0.0003 \\
\hline $\mathrm{N}$ & 0.5 & 0.5 \\
\hline
\end{tabular}

In terms of fracture the respective values for vfn are 0.3 for the AM and 1.3 for the wrought maraging steel.

\subsubsection{Comparison of model with QS tests}

The comparison of the model with the isothermal stress versus strain curves for AM maraging steel is given in Figure 3for QS 373K and $1 \mathrm{~s}^{-1}$. The level of agreement is very good for the general stress versus strain response. There is a larger spread in data for the higher strain rate test particularly at very low strains.

\section{High Strain Rate Tensile Tests}

Performing high strain rate tensile tests for very high strength materials using a Tensile Split Hopkinson Pressure Bar (TSHPB) presents a significant technical challenge. The key issue is ensuring the specimen deforms plastically whilst the grips stay elastic. For this reason the entire TSHPB system employed at The University of Cambridge had to be redesigned.

The bar material was changed to grade 5 titanium alloy and a novel screw thread system (Sprialock) was used so that the loading was spread through all the threads rather than being concentrated on the first one or two threads. A general diagram of the TSHPB is given in Figure 4.

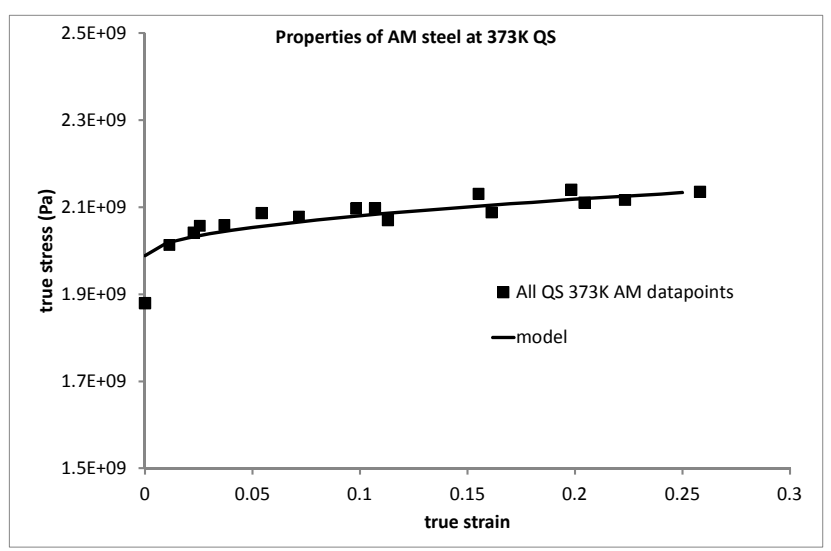

(a)

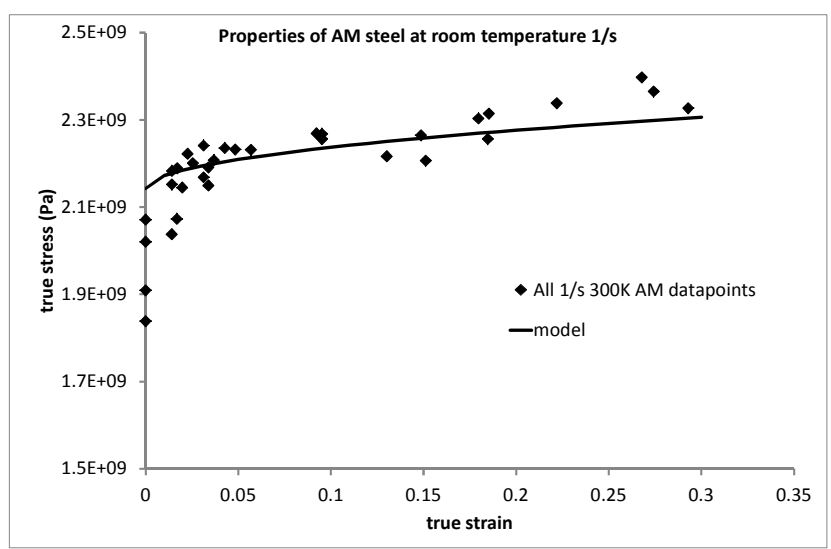

(b)

Fig. 3. Comparison of modified $A / Z$ model with isothermal curves for AM maraging steel.

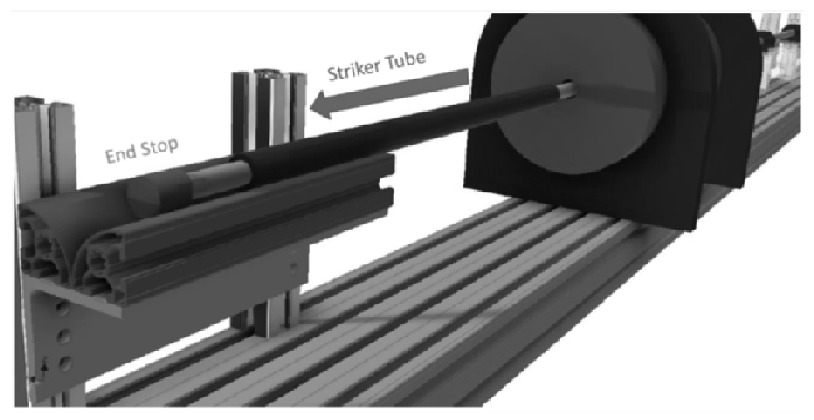

Fig. 4. Schematic of layout for TSHPB.

The system was extensively calibrated so the force in the bar could be related to the stress in the specimen given the standard assumptions in the Hopkinson Bar analysis. The tests were very successful and there was no evidence of the threads exhibiting plastic deformation.

High speed video of the specimens clearly showed that the AM maraging steel exhibits a pronounced neck before fracture as shown in Figure 5. Although not as ductile as the wrought material this is a highly encouraging result since it provides scope to improve the ductility of the material further through improvements in the microstructure. 


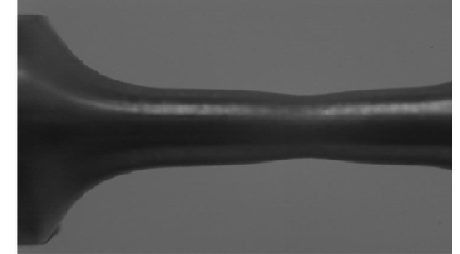

Fig. 5. High speed video of $A M$ maraging steel high rate tensile test.

In addition a highly novel method for measuring the strain has been developed by using the machining marks on the specimen as fiducial marks. The machining marks are an integral part of the specimen and therefore move with it when it deforms. In this way, if they are tracked, it allows for a measure of the pre-necking bulk strain in the specimen to be calculated. This technique has been utilised using two methods. The first utilises the periodicity of the marks, as shown in Figure 6. If the lines are averaged vertically it gives a $1 \mathrm{D}$ dataset where the intensity varies with horizontal position (i.e. along the deformation axis of the sample). Taking a Fourier transform of this data gives a frequency spectrum related to the periodicity of the dark and light bands. As the sample deforms the frequency content of the data changes and can be related back to the expansion of the sample to calculate the strain.

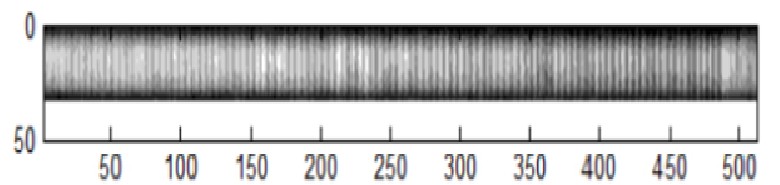

Fig. 6. Machining marks on specimen.

If the machining marks are not sufficiently periodic then the Fourier method does not work. The alternative approach averages the marks vertically for each time step and then superimposes each time step to produce a pseudo-streak image. In the image, shown in Figure 7 , the horizontal axis shows position in the sample and the vertical axis the time (starting at the top and running to the bottom). When the sample is stationary the lines are vertical, while straining they are at an angle and diverge.

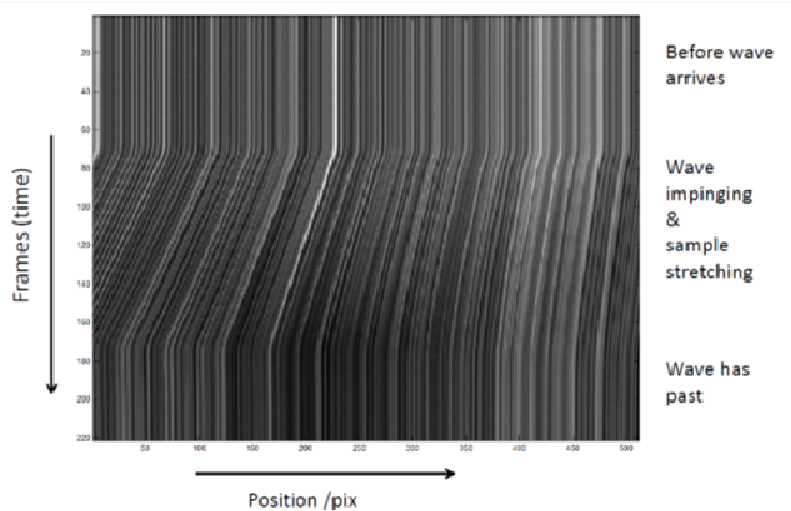

Fig. 7. Pseudo-streak image of a sample undergoing deformation.
This can then be converted into a graph of engineering strain versus time as shown in Figure 8.

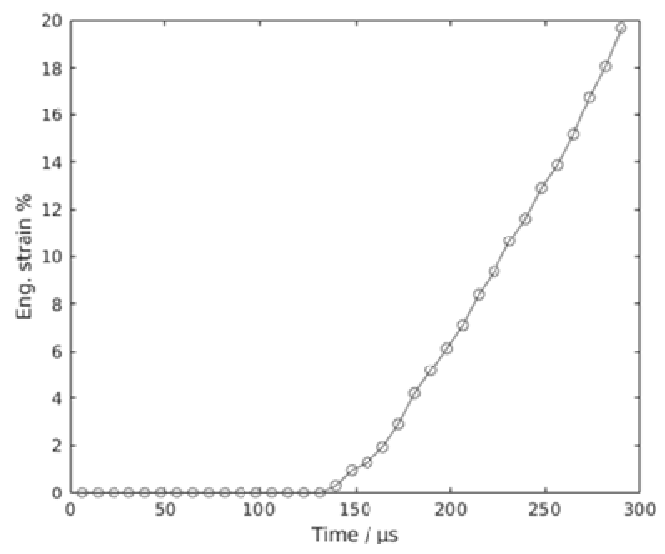

Fig. 8. Graph of engineering strain versus time for AM sample.

The resulting dynamic stress versus strain curves are shown in Figure 9. The form of the curves are very similar for wrought and AM maraging steel in that each reach a peak stress of $2.2 \mathrm{GPa}$ before reducing with increasing strain due to thermal softening in the neck region. The results are also very reproducible and there was no evidence of anisotropic behaviour.

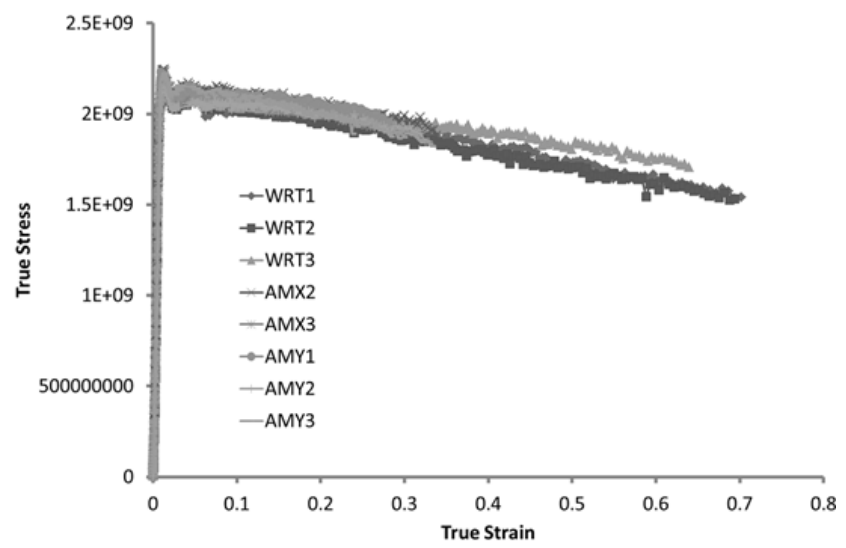

Fig. 9. Dynamic true stress versus true strain curve for wrought and AM maraging steel.

Simulations were performed based on the loading of the specimen only and comparison with the raw data for the reduction of area is shown in Figure 10.

Whilst this level of agreement is good and is similar for the raw elongation data, the agreement with the dynamic stress versus strain curve was only within $10 \%$. The reason for this is that the simulation only considered the direct loading on the specimen, whereas the loading is derived from the strain gauge record. To resolve this issue the simulations need to model the whole TSHPB apparatus so they can exactly replicate the loading compared to the strain gauge record. This is not completely straightforward as the simulations also have to account for the gripping of the specimen. 


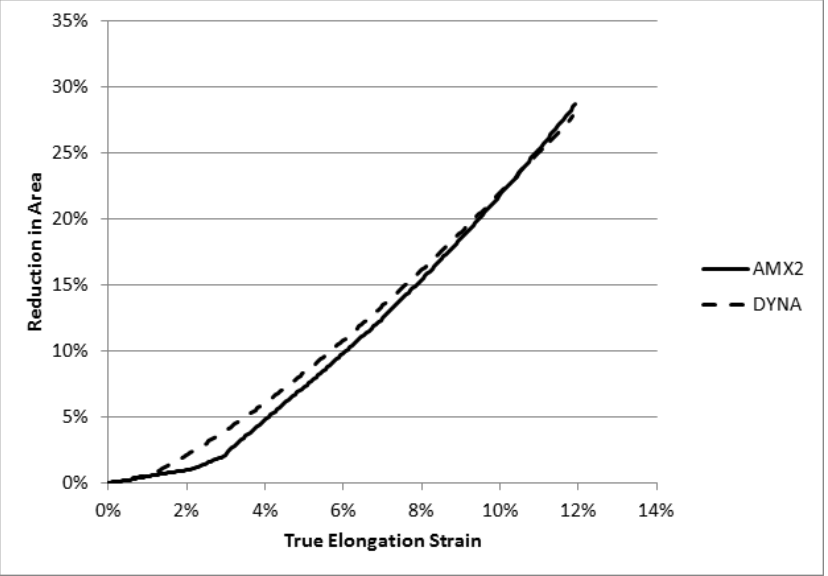

Fig. 10. Comparison of simulation and experiment for Reduction in area.

\section{Microstructural Analyses}

Samples of the AM and wrought materials were subject to metallographic preparation to characterise the general microstructure and the nature of any inclusions and imperfections. X-ray diffraction was also applied to identify the presence of crystalline inclusions and quantify the presence of any retained austenite phase from material heat treatment or associated with the AM manufacturing process. In addition, scanning electron microscopy was performed on the tensile specimens (including TSHPB samples) after testing to investigate the fracture surfaces.

All of the fracture surfaces for all conditions for the wrought and AM maraging steel were ductile and a typical example is given in Figure 11. This shows the presence of ductile dimple/microvoid coalescence features and inclusions.

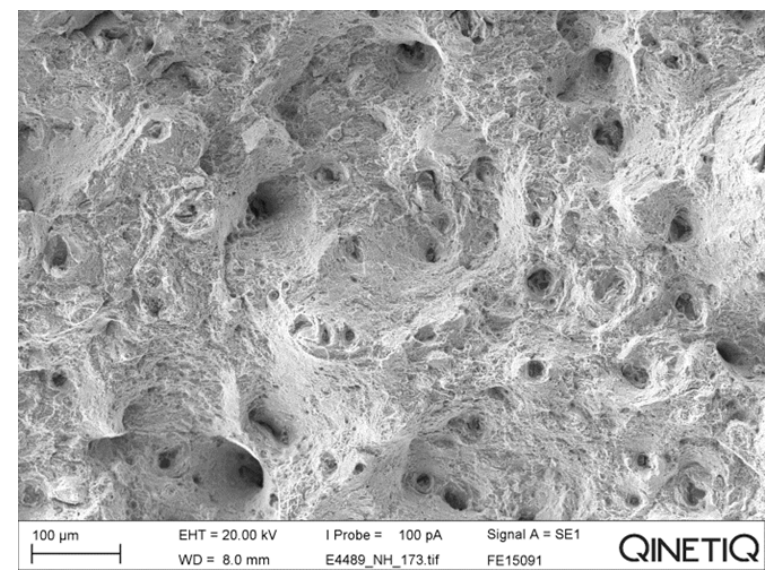

Fig. 11. Fracture surface of AM maraging steel.

The general microstructure between the wrought and AM maraging steel is very different as shown in Figure 12.

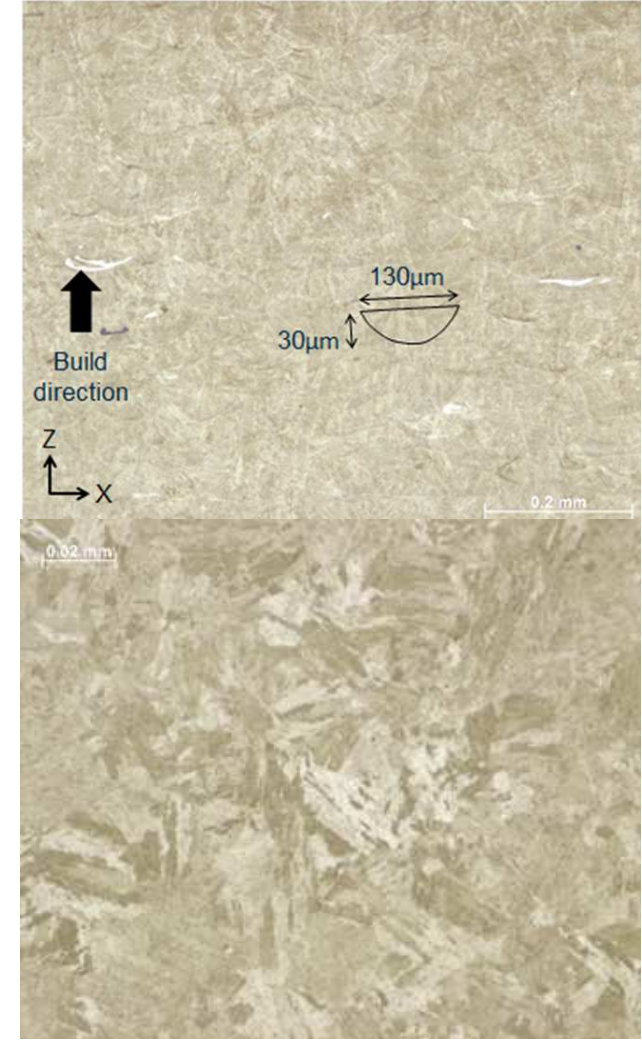

Fig. 12. Microstructure of AM (top) and wrought maraging steel.

A number of microstructural features apparently characteristic of the AM process were present; Figure 13 shows nickel-rich "white" phase and a titanium-rich "feathery" phase within the structure, along with a number of near spherical or globular oxide inclusions.
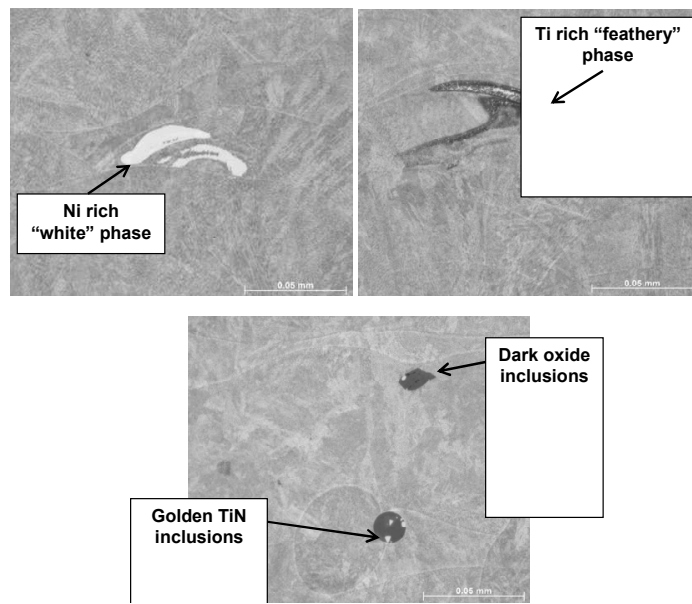

Fig. 13. Details of phases and oxide and nitride inclusions.

Further compositional analysis has determined these inclusions to be a mixture of titanium nitrides (yellow in appearance), and titanium/aluminium oxides (the titanium and aluminium present in the maraging steel composition having the greatest affinity for any oxygen present during deposition of each layer). This is suggestive that the globular inclusions probably form by oxidation / nitridation reactions in the fusion pool with the protective atmosphere (believed to be argon with a 
low residual oxygen content) of the AM deposition machine during each layer build.

\section{Discussion}

The results for the AM maraging steel are very promising in that they exhibit higher proof stress and UTS than the wrought maraging steel. The ductility of the AM material, whilst not as high as for the wrought, is much higher than expected and the AM material is capable of supporting quite large (i.e. 30\%) plastic strains. However, the wrought material is much more expensive than the AM material and so it could be very cost effective through the economies of scale in manufacture.

The reduced ductility for the AM material compared with that of the wrought material reflects the higher number of inclusions, which act as localisation points for void growth leading to ductile fracture. However, the AM process gives rise to possibilities that the number of inclusions can be reduced through improved quality control of the powder/wire source material and the processing environment. This could then allow the development of very strong and ductile materials which would be beneficial for a range of structural and impact applications. Furthermore the potential economies of scale from AM could make bespoke components cost effective.

This allows for the potential of designing material with bespoke properties, e.g. fracture under certain loading conditions as well as the development of novel multilayer and graded density materials.

This work was funded by the Defence Science and Technology Laboratory through the Weapons Science and Technology Centre. We would like to acknowledge the contribution of 3T in the supply and advice of the AM maraging steel.

\section{Conclusions}

The AM material was much more ductile than expected (i.e. $4-5 \%$ compared to $1.5 \%$ elongation) for all conditions tested, although not as ductile as the wrought material under all conditions tested. A TSHPB specifically for testing high strength materials has been commissioned at The University of Cambridge and is a unique UK capability. The high strain rate behaviour of the AM and wrought materials are very similar under high rate tensile loading in terms of stress level and there was no evidence of anisotropy. The microstructure for the AM material was consistent throughout the sample but very different from the wrought material. The AM material exhibited a greater number of inclusions than the wrought material due to the powder processing route. All the fracture surfaces exhibited ductile failure associated with the inclusions.

\section{References}

1. K. Kempen, E Yasa, L Thijs, J-P Kruth, J Van Humbreeck, Phys Proc 12 255-263 (2011)

2. E Jagle, Z Sheng, L Wu, L Lu, J Risse, A Weisheit, D Raabe, JOM, Vol 68, No 3 (2016)

3. R Armstrong, F Zerilli, Jnl de Phys IV 49 C3 529 (1988)

4. A Butler, P Church, B Goldthorpe, Jnl de Phys IV, C3-917 (1991)

5. B Goldthorpe, Jnl de Phys IV 7 C3 891 (1997)

6. P Bridgeman, Large Plastic Flow and Fracture (Mcgraw-Hill, 1952) 